original article. If an American researcher includes work done in Europe, or vice versa, it is often because the reviewers or an editor, after seeing the original submission, have reminded the authors that this is an international journal. Authors are then urged to be sure to review the literature from other countries and eventually most do. But the tendency to be insular, to neglect the work of colleagues from abroad, is deplorably distressing and reflects poorly on the scientist.

Returning to preventing drowning, these contributions and much of the literature support the belief that the best solution remains some way to physically separate the child from the danger. Other possible solutions require further study; the benefits of teaching swimming skills early, various life saving techniques, the design of small boatsand the safety equipment they must provide. All of these make sense but await solid evidence. Until such evidenc $\bar{\oplus}$ becomes available, drowning is likely to remain 'the finaf frontier' of injury prevention.

1 Asher KN, Rivara FP, Felix D, Vance L, Dunne R. Water safety training a a potential means of reducing risk of young children's drownings. Injurf Prevention 1995; 1: 228-33.

\title{
An exceptionally impressive annual report
}

I was tempted to title this, 'Gob-smacked by an annual report', but I was persuaded that this was undignified and mysterious. The strange phrase originates in England, where it conveys being surprised or overwhelmed (usually, in a positive way). This was my reaction to reading the 1996 annual report of Monash University's Accident Research Centre (MUARC). I get many such reports and am pleased to have them. I hope others will not feel neglected that I am singling this out for praise. I do so because it is one of the most recent I have read that has elicited such a strong reaction.

Before explaining why I reacted as I did, I should remind readers that MUARC is directed by Peter Vulcan, a member of our editorial board. As we noted earlier, Professor Vulcan recently received two honours from the US: he is the first non-American to receive a Distinguished Career Award from the American Public Health Association as well as a Special Award of Appreciation from the National Highway Safety Administration.

But it is not Vulcan's well deserved recognition that caught my attention. Apart from how well it is written and illustrated, to say nothing of the quality of the paper and binding, two elements are noteworthy: in the section on research, a large chunk is devoted to 'Evaluations'. These include one dealing with airbag effectiveness, another with a 'black spot' program, and a third on new road safety programs. The latter, for example, describes an $11 \%$ reduction in casualty crashes after the introduction of mobile radar devices.

In the section entitled 'Longer Term Research', there is $\$$ description of a program dealing with consumer produco safety; another with young drivers; one describing changes in farm fatalities; and another showing a decline im unintentional home injuries after the introduction of a Safe. Community program in La Trobe Valley.

Most impressive was the section 'Translating Research' into Action'. Ranging from simple measures to preveno finger jams from doors, attempts to reduce child poisoning using an informative brochure, to more complex road safet measures, these are the sort of responses we all hope fo? from our research. Whether they are effective is the subject of still further research. But the examples are a large step i the right direction.

What does all this cost? To be precise, \$A466 500 shared by RACV Ltd, the Transport Accident Commission: and VicRoads - wise, cost effective investments. Iక్ MUARC better than its many counterparts in the UK the US, and elsewhere? Perhaps not, but that is not the issue. They deserve this recognition for this compelling report and for the wise mix of basic and applied research? (Now all that is needed is to persuade them to substitute 'injury' for 'accident' in their title!)

\section{$\star \star \star \star \star \star$}

\section{Great expectations}

The appointment in the UK of a Minister of Public Health is to be applauded. It is especially welcome because from statements Tessa Jowell has made, it seems likely that injury prevention will be high on her agenda. If it is not, it most certainly should be. She has made a clear commitment to reducing inequalities between rich and poor and there are few areas where these inequalities are more apparent than injury mortality. She states that social factors 'have for too long been regarded as peripheral to health policy' and adds, 'Public health has been marginalized, and its laws and structures have been neglected'. Although neither the word 'accident' or 'injury' appears in this report, my reaction to the tone of her comments is, "What a welcome breath of fresh air!'

As far as I know, few countries have created a comparably senior public health position. In the US, the Surgeon General has some responsibilities in this domain, and during the days when Everett Koop held this position, child injury prevention gained considerable prominence.
The existence of the National Center for Injury Prevention and Control at the Centers for Disease Control and Prevention is also important, and although not 'publicw health' in the strict sense, it serves as a high profiles standard bearer. In Canada, the deputy minister respone sible for the Laboratory Center for Disease Control is involved in some aspects of injury prevention, but does not have responsibilities equivalent to Jowell's. I don't know what the situation is in other countries, but I suspect that few have a Minister for Public Health but I believe thas most should, providing, of course, that the ministe? understands that injuries are a public health problem of major significance.

Similarly, the appointment in the UK of Glendo Jackson as Transport Minister, is also encouraging. Preso reports suggest that she recognizes that her portfolio involves more than simply moving more cars, more quickly. She is concerned about the environment, and alternatives to cars. 'I used to ride to school, but, since 